\title{
Flu times two
}

\section{Catching Cold: 1918's Forgotten Tragedy and the Scientific Hunt for the Virus That Caused It By Pete Davies}

Michael Joseph \$34.99 (Can.). ISBN 0-718-14349-3, 1999

\section{Flu: The Story of the Great Influenza Pandemic of 1918 and the Search for the Virus That Caused It By Gina Kolata}

Farrar, Straus and Giroux, \$25.00 (US). ISBN 0-374-15706-5, 1999

Reviewed by Brian W.J. Mahy

National Center for Infectious Diseases,

Centers for Disease Control and Prevention, Atlanta, Georgia 30333, USA

The genetic material of the type A influenza virus, the only one of the three types that is known to cause pandemic influenza, consists of eight segments of single-stranded RNA encoding ten proteins. The most important surface antigen, haemagglutinin (an attachment protein), has considerable diversity, generated by mutation and subsequent selection of antigenic variants that can evade the host's antibody response. Variation in another surface protein, neuraminidase, may also assist in immune evasion. This 'antigenic drift' necessitates the production of new influenza vaccines every year. New variants of influenza also arise through genetic reassortment be-

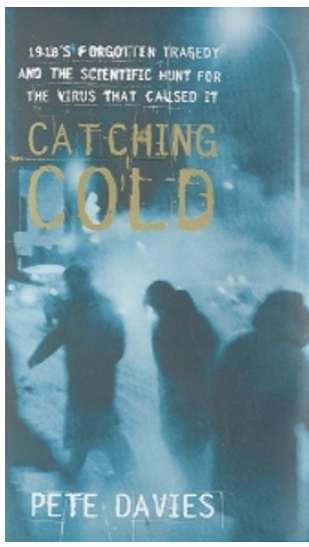
Influenza viruses were first isolated from swine by Richard Shope in 1931 and from humans by Smith, Andrewes and Laidlaw in 1933. The pandemic of 1918 caused an estimated 25 million deaths worldwide, and over the 50-year period following virus isolation (until the discovery of HIV), more work was carried out on the properties and replication of influenza than on any other viral pathogen. But a major unsolved question has been why the 1918 influenza virus, popularly known as 'Spanish flu', was so highly pathogenic. Records from the period suggest that this particular strain was unique in its propensity to cause fatal pneumonia, especially in young adults.

Although attempts were tween a human influenza virus and another influenza A virus (usually an avian or swine virus). When the RNA segment encoding haemagglutinin is replaced by one of distinct antigenicity (described as a new subtype), and when such a reassorted virus is highly transmissible among humans, the virus spreads rapidly and may cause a global pandemic. Whether such a reassortment event was responsible for the appearance of the 1918 virus (H1 subtype) is unknown, but it seems to have been involved in generating the Asian influenza pandemic in 1957 (H2 subtype) and the Hong Kong influenza pandemic in 1968 (H3 subtype). There is now considerable concern among virologists that a new subtype could appear at any time. As detailed in two recent books on the 1918 outbreak, Catching Cold, by Pete Davies, and Flu, by Gina Kolata, new technologies have allowed a re-examination of the 1918 pandemic as well as some of the events that followed. mafrost region, these efforts were unsuccessful. The more recent availability of PCR to amplify the viral RNA, both from formalin-fixed tissues and from tissue samples taken recently from victims buried in the permafrost since 1918, has provided the complete sequence of the gene encoding haemagglutinin and should soon lead to determination of the sequences of the other nine genes of the 1918 virus.

The story behind this recent success has been recounted in Catching Cold and Flu, which rely heavily upon the historical accounts provided by Alfred Crosby's definitive work, America's Forgotten Pandemic (published in 1989), for their descriptions of the events in 1918. The books agree on most of the facts concerning several recent influenza investigations. These investigations include, in both books, the 1997 incident when six of eighteen persons infected with an avian influenza virus (H5 subtype) died in Hong Kong; the attempt to find the 1918 influenza virus in the remains of eight miners buried in the Norwegian permafrost in Svalbard; and the superb work carried out by Jeffery Taubenberger's group at the Armed Forces Institute of Pathology in Washington in which the RNA of the 1918 virus was amplified and sequenced from formalin-preserved tissue specimens of two United States soldiers. Also detailed is the remarkable story of Johan Hultin, who single-handedly went to Alaska and retrieved tissue specimens from an influenza victim who had been buried in the permafrost since 1918. The Taubenberger group used RNA from this victim to corroborate their findings from the formalin-fixed tissues (A.H. Reid et al. Proc. Natl Acad. Sci. USA 96, 1651-1656; 1999).

Both books are popular accounts written more for the interested lay reader than for the scientist. Flu emphasizes events in the US, and it contains an interesting and detailed account of the abortive attempt during President Ford's administration to vaccinate the entire US population against swine flu and the litigation nightmare that ensued. Catching Cold offers a useful account of the recent development of anti-influenza drugs which have been designed on the basis of new knowledge of the threedimensional structure of neuraminidase. Davies calls these "plug drugs" because they are built to plug a cleft on the neuraminidase surface and stop its enzymatic function.
There are many lessons to be learned in Flu and Catching Cold which may be of value in preparing for the inevitable future pandemics of influenza. Both books express well the sense of excitement in uncovering the mystery of the 1918 influenza virus. But the story is not yet over. The sequence of the haemagglutinin gene did not provide any obvious clues as to why the virus was so pathogenic. It remains to be seen whether answers to this question will come from the sequences of the other nine genes. Thus the definitive account of the 1918 influenza pandemic has yet to be written. 